\title{
Influence of Bitartrate Ion Concentration in the Copper Electrodeposition Onto a Polycrystalline Gold Electrode
}

\author{
Miguel Hernández, ${ }^{1}$ (1) Giaan A. Álvarez-Romero, ${ }^{1}$ (1) Margarita Rivera, ${ }^{2}$ (i) Simplicio González-Montiel, ${ }^{1}$ \\ Clara H. Rios-Reyes, ${ }^{3}$ ([) Luis H. Mendoza-Huizar ${ }^{1, *}$

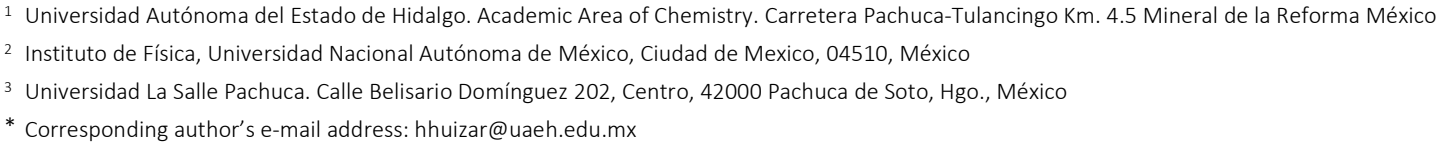

RECEIVED: March 23, 2021 * REVISED: June 9, 2021 * ACCEPTED: June 10, 2021

Abstract: In the present work, the influence of the concentration of bitartrate ions (HT) on the copper electrodeposition process was analyzed. The study was carried out from an aqueous solution containing $0.001 \mathrm{M}$ of $\mathrm{CuX}$ (where $\mathrm{X}=\left(\mathrm{NO}_{3}{ }^{-}\right)_{2},\left(\mathrm{Cl}^{-}\right)_{2}, \mathrm{SO}_{4}{ }^{2-}$ ) and $x \mathrm{M} \mathrm{KHT}$ (where $x=0.005 \mathrm{M}$, $0.01 \mathrm{M}$, and $0.015 \mathrm{M}$ ). From voltammetric and chronoamperometric studies, the results indicate that copper electrodeposition is a diffusioncontrolled process. The current density transients were well described through a kinetic mechanism involving capacitive and faradaic contributions. The diffusion coefficient values of $\mathrm{Cu}^{1+}$ and $\mathrm{Cu}^{2+}$ result to be similar at the different concentration values of potassium bitartrate used in this work.

Keywords: copper, acid bitartrate ions, kinetic, copper, electrodeposition

\section{INTRODUCTION}

C OPPER is one of the most widely used metals in electroplating due to its numerous technological and decorative applications. ${ }^{[1,2]}$ At industrial scale, cyanidebased alkaline copper solutions have probably been the preferred choice for producing a high quality copper plating. However, cyanides are toxic compounds, which act as metabolic inhibitors, ${ }^{[3]}$ and larger amounts of cyanides released into solid waste and wastewater from the metal plating industry can become an environmental issue. ${ }^{[3]}$ In this sense, several attempts have been made to electrodeposit copper from non-cyanide solutions based on ecological complexing agents such as glutamate, ${ }^{[4]}$ citrate, ${ }^{[5]}$ glycine, ${ }^{[6]} \mathrm{EDTA}^{\left[{ }^{[7]}\right.}$ ammonia, ${ }^{[8]}$ and tartrate. ${ }^{[9]}$ Specifically, tartaric acid ( $\mathrm{HOOC}-\mathrm{CH}(\mathrm{OH})-\mathrm{CH}(\mathrm{OH})-\mathrm{COOH}$ ) and sodium potassium tartrate (Rochelle salt) have been used in the electrochemical and electroless plating process of copper. ${ }^{[10,11]}$ In addition, this type of bath involves easy waste treatment options and allows the electroplating of copper at low plating rates and temperatures. ${ }^{[12]}$ However, to our knowledge, the two main tartaric acid salts, potassium bitartrate (KHT) and calcium tartrate (CaT), have not been used as part of the composition of copper plating baths. Probably, it is because CaT and KHT are not very soluble in water, $0.1 \mathrm{~g} \mathrm{~L}^{-1}$ and $6.2 \mathrm{~g} \mathrm{~L}^{-1}$ respectively, in comparison with tartaric acid $\left(206 \mathrm{~g} \mathrm{~L}^{-1}-1250 \mathrm{~g} \mathrm{~L}^{-1}\right)$. In an aqueous solution, $\mathrm{CaT}$ is dissociated to $\mathrm{Ca}^{2+}$ and $\mathrm{T}^{2-}$ ions, but the concentration of tartrate ions from this dissociation is extremely low due to its low solubility. On the other hand, KHT dissociates in solution to potassium ions and weakly acidic bitartrate (HT) ions, where HT exhibits a limiting conductance value of $29.4 \pm 0.2 \mathrm{~cm}^{2} \mathrm{ohm}^{-1}$ equiv ${ }^{-1}$. Here, it is interesting to mention that some authors have reported a strong adsorption of bitartrate ions onto a $\mathrm{Cu}(110)$ surface, ${ }^{[13]}$ which may modify the nucleation and growth process. Nevertheless, to our knowledge, HT ions do not form complexes with copper ions and their effect on the copper electrodeposition process has not yet been analyzed in the literature. In order to analyze the design of 
an environmentally friendly copper bath based on HT ions, we studied the influence of their concentration on the electrodeposition of copper on a polycrystalline gold electrode.

\section{EXPERIMENTAL}

Copper electrodeposits onto a polycrystalline gold electrode were carried out from an aqueous solution containing $0.001 \mathrm{M}$ of $\mathrm{CuX}$ (where $\mathrm{X}=\left(\mathrm{NO}_{3}{ }^{-}\right)_{2},\left(\mathrm{Cl}^{-}\right)_{2}, \mathrm{SO}_{4}{ }^{2-}$ and $x$ M KHT (where $x=0.005 \mathrm{M}, 0.01 \mathrm{M}$, and $0.015 \mathrm{M}$ ) at $\mathrm{pH}=3.5$. All solutions were prepared using analytic grade reagents with ultrapure water (Millipore- $Q$ system) and were deoxygenated by bubbling $\mathrm{N}_{2}$ for $15 \mathrm{~min}$ before each experiment. The working electrode was a polycrystalline gold tip provided by $\mathrm{BAS}^{\mathrm{TM}}$, with $0.02 \mathrm{~cm}^{2}$ of area, the exposed surface was polished to a mirror finish with different grades of alumina down to $0.05 \mu \mathrm{m}$ and ultrasonically cleaned before experiments. A graphite bar with an exposed area greater than the working electrode was used as counter electrode. A saturated silver electrode $(\mathrm{Ag} / \mathrm{AgCl})$ was used as reference electrode, and all the measured potentials are referred to this scale and at $25^{\circ} \mathrm{C}$. The electrochemical experiments were carried out in a BASI-Epsilon potentiostat connected to a personal computer running the EC-Epsilon software to allow the control of experiments and data acquisition. In order to verify the electrochemical behavior of the electrode in the electrodeposition bath, cyclic voltammetry was performed in the 0.700 to $-0.400 \mathrm{~V}$ potential range at the scan rates $20,40,60,80,100,120,240$ and $300 \mathrm{mV} \mathrm{s}^{-1}$. The kinetic mechanism of copper deposits onto Au was studied under potentiostatic conditions by means of the analysis of the experimental current density transients obtained with the potential step technique. The perturbation of the potential electrode always started at $0.650 \mathrm{~V}$ and the potential step was varied in the [0.2 to -0.160$] \mathrm{V}$ zone, during $32 \mathrm{~s}$.

\section{RESULTS AND DISCUSSION}

It is well known that the presence of specific chemical species in the deposition bath can induce changes in the thermodynamic and the kinetic parameters during the electrodeposition process. In the case of the copper electrodeposition process, the influence of HT concentration has not been reported in the literature yet. $\mathrm{HT}$ ions can be obtained from KHT, which is dissociated to potassium ions and weakly acidic bitartrate (HT) ions, according to Equation (1). ${ }^{[11]}$

$$
\mathrm{KHC}_{4} \mathrm{H}_{4} \mathrm{O}_{6}(\mathrm{~s}) \leftrightarrow \mathrm{K}^{+}(\mathrm{aq})+\mathrm{HC}_{4} \mathrm{H}_{4} \mathrm{O}_{6}{ }^{-}(\mathrm{aq})
$$

Also, it is important to consider that acid bitartrate ions, in aqueous media, are dissociated according to Equation (2)

$$
\mathrm{HC}_{4} \mathrm{H}_{4} \mathrm{O}_{6}{ }^{-}(\mathrm{aq})+\mathrm{H}_{2} \mathrm{O}(\mathrm{I}) \rightarrow \mathrm{C}_{4} \mathrm{H}_{4} \mathrm{O}_{6}{ }^{2-}(\mathrm{aq})+\mathrm{H}_{3} \mathrm{O}^{+}(\mathrm{aq})
$$

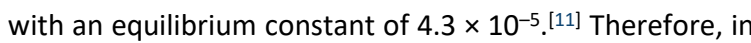
our experimental conditions $(\mathrm{pH}=3.5)$, the dissociation of HT into hydrogen and tartrate ions can be neglected, and the influence of HT ions may be analyzed.

\section{Voltamperometric Study}

Figure 1 shows a typical cyclic voltammogram obtained from the system $\mathrm{Au} / 0.001 \mathrm{M}$ of $\mathrm{Cu}\left(\mathrm{NO}_{3}\right)_{2}+0.01 \mathrm{M} \mathrm{KHT}$ at a scan rate of $20 \mathrm{mV} \mathrm{s}^{-1}$ (broken line). The potential scan was started at $0.6 \mathrm{~V}$, in the negative potential direction up to $-0.4 \mathrm{~V}$, and then reversed to the starting potential. From this Figure, it is clear the formation of two main current density peaks $A$ and $B$ at $0.110 \mathrm{~V}$ and $-0.100 \mathrm{~V}$, respectively, while in the anodic region can be observed the formation of the peaks $\mathrm{B}^{\prime}$ and $\mathrm{A}^{\prime}$ at $0.097 \mathrm{~V}$ and $0.280 \mathrm{~V}$, respectively. The comparison of this voltamperogram with the obtained from the system $\mathrm{Au} / 0.01 \mathrm{M} \mathrm{KHT}$ at a scan rate of $20 \mathrm{mV} \mathrm{s}^{-1}$, indicates that peaks $A$ and $B$ correspond to the copper reduction processes, while $A^{\prime}$ and $B^{\prime}$ to the oxidation of the copper electrodeposited at the direct scan.

In order to establish the correspondence among peaks $A$ and $A^{\prime}$ and $B$ with $B^{\prime}$, it was carried out a voltamperometric study at different inversion potentials and at a constant scan rate $\left(20 \mathrm{mV} \mathrm{s}^{-1}\right)$ as shown in Figure 2 . Note that at the inversion potential value of $0 \mathrm{mV}$, the peak $A$ is fully formed, if the scan potential is inverted to the anodic zone, it is clear the formation of the anodic signal $A^{\prime}$. Last result indicates that peak $A$ is associated with peak $A^{\prime}$. Also, if we extended the direct scan to more negative potentials, than $-0.08 \mathrm{~V}$, it is evident the formation of the cathodic peak $B$, while that in the anodic zone is clear the formation

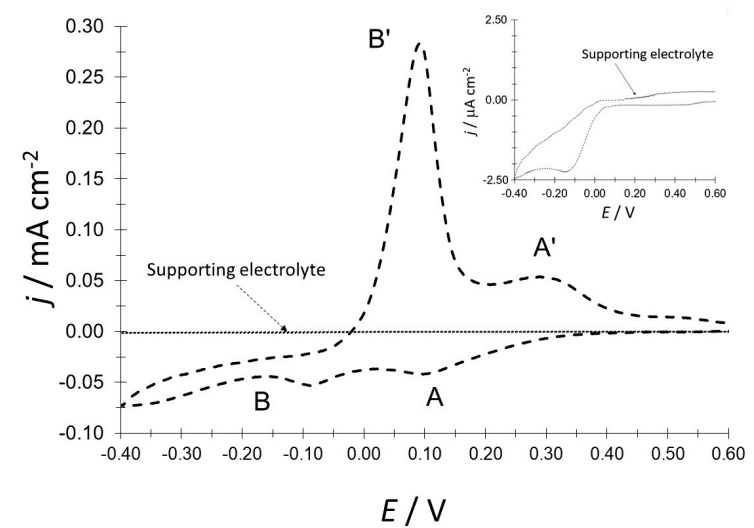

Figure 1. A typical cyclic voltammogram obtained from the $\mathrm{Au} / 0.001 \mathrm{M}$ of $\mathrm{Cu}\left(\mathrm{NO}_{3}\right)_{2}+0.01 \mathrm{M} \mathrm{KHT}$. The potential scan rate was started at $0.600 \mathrm{~V}$ toward the negative direction with a potential scan rate of $20 \mathrm{mV} \mathrm{s}^{-1}$, the voltammogram associated with the supporting electrolyte is indicated as an inset. 


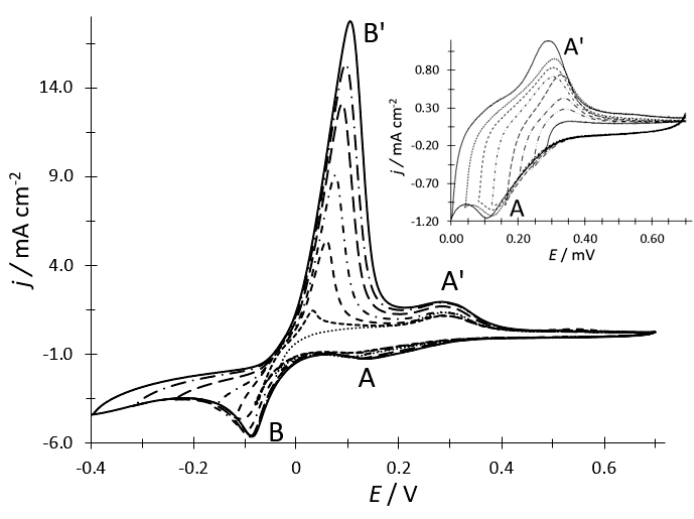

Figure 2. Cyclic voltammograms obtained from the $\mathrm{Au} / 0.001$ $\mathrm{M}$ of $\mathrm{Cu}\left(\mathrm{NO}_{3}\right)_{2}+0.01 \mathrm{M} \mathrm{KHT}(\mathrm{pH}=3.5)$ system at different inversion potentials. In all cases, the potential scan started at $0.700 \mathrm{~V}$ towards the negative direction with a potential scan rate of $20 \mathrm{mV} \mathrm{s}^{-1}$. Cathodic current density peaks (A and $B$ ) and anodic peaks ( $\mathrm{B}^{\prime}$ and $\mathrm{A}^{\prime}$ ) are indicated.

of peak $\mathrm{B}^{\prime}$, only when the inversion potential is lower than $-0.08 \mathrm{~V}$. This last result indicates that peak $B$ is related to $B^{\prime}$.

Peak $A$ has been associated with the reduction of cupric to cuprous ions, followed by the disproportionation of the produced cuprous ions into metallic copper and cupric ions, reaction (3): ${ }^{[14]}$

$$
\begin{aligned}
& 2 \mathrm{Cu}\left(\mathrm{H}_{2} \mathrm{O}\right)_{6}^{2+}+2 \mathrm{e}^{-} \rightarrow 2 \mathrm{Cu}\left(\mathrm{H}_{2} \mathrm{O}\right)_{4}^{+}+4 \mathrm{H}_{2} \mathrm{O} \rightarrow \\
& \rightarrow \mathrm{Cu}^{0}+\mathrm{Cu}\left(\mathrm{H}_{2} \mathrm{O}\right)_{6}^{2+}+6 \mathrm{H}_{2} \mathrm{O}
\end{aligned}
$$

while peak $B$, corresponds to the reduction of cupric ions (from the bulk and those produced from the reaction (3)) to metallic copper, according to the following reaction:

$$
\mathrm{Cu}\left(\mathrm{H}_{2} \mathrm{O}\right)_{6}^{2+}+2 \mathrm{e}^{-} \rightarrow \mathrm{Cu}^{0}+6 \mathrm{H}_{2} \mathrm{O}
$$

peak $\mathrm{B}^{\prime}$ corresponds to the oxidation of metallic copper to cupric ions, ${ }^{[14,15]}$ according to the following reaction

$$
\mathrm{Cu}^{0}+6 \mathrm{H}_{2} \mathrm{O} \rightarrow \mathrm{Cu}\left(\mathrm{H}_{2} \mathrm{O}\right)_{6}^{2+}+2 \mathrm{e}^{-}
$$

On the other hand, the reaction between the cupric ions accumulating on the surface, see Equation (5), and the remainder of metallic copper causes the appearance of peak $A^{\prime} \cdot{ }^{[14,15]}$ This may be explained through the Equations (6) and (7)

$$
\begin{aligned}
& \mathrm{Cu}^{0}+\mathrm{Cu}\left(\mathrm{H}_{2} \mathrm{O}\right)_{6}^{2+} \rightarrow 2 \mathrm{Cu}\left(\mathrm{H}_{2} \mathrm{O}\right)_{4}^{+}+2 \mathrm{H}_{2} \mathrm{O} \\
& \mathrm{Cu}\left(\mathrm{H}_{2} \mathrm{O}\right)_{4}^{+}+2 \mathrm{H}_{2} \mathrm{O} \rightarrow \mathrm{Cu}\left(\mathrm{H}_{2} \mathrm{O}\right)_{6}^{2+}+\mathrm{e}^{-}
\end{aligned}
$$

Thus, the chemical reaction between $\mathrm{Cu}^{0}$ and $\mathrm{Cu}\left(\mathrm{H}_{2} \mathrm{O}\right)_{6}^{2+}$ produces $\mathrm{Cu}\left(\mathrm{H}_{2} \mathrm{O}\right)_{4}^{+}$which reacts with $\mathrm{H}_{2} \mathrm{O}$ to form $\mathrm{Cu}\left(\mathrm{H}_{2} \mathrm{O}\right)_{6}^{2+} .[14,15]$

Similar results to those reported in Figure 2, were obtained for the systems $\mathrm{Au} / 0.001 \mathrm{M}$ of $\mathrm{CuCl}_{2}+0.005 \mathrm{M}$ $\mathrm{KHT}(\mathrm{pH}=3.5)$ and $\mathrm{Au} / 0.001 \mathrm{M}$ of $\mathrm{CuSO}_{4}+0.015 \mathrm{M} \mathrm{KHT}$ $(\mathrm{pH}=3.5)$, see Figure 3 . Suggesting that the type of copper salt does not affect the copper electroplating process.

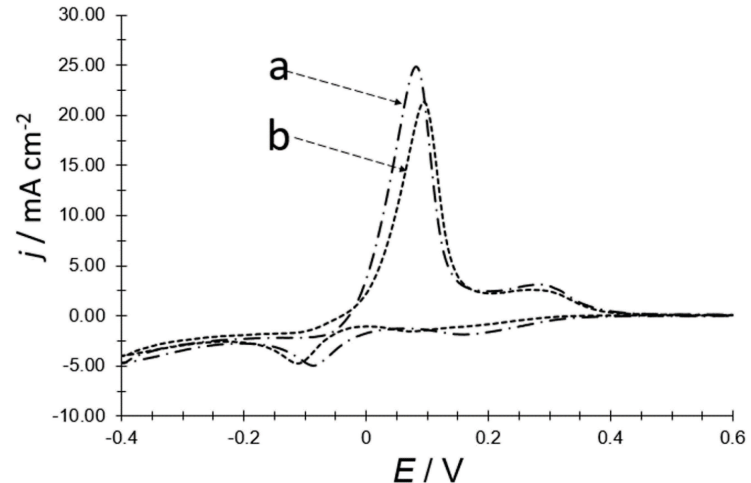

Figure 3. Cyclic voltammograms obtained from a) $\mathrm{Au} / 0.001 \mathrm{M}$ of $\mathrm{CuCl}_{2}+0.005 \mathrm{M} \mathrm{KHT}(\mathrm{pH}=3.5)$ and b) $\mathrm{Au} / 0.001 \mathrm{M}$ of $\mathrm{CuSO}_{4}+0.015 \mathrm{M} \mathrm{KHT}(\mathrm{pH}=3.5)$. In all cases, the potential scan started at $0.600 \mathrm{~V}$ towards the negative direction with a potential scan rate of $20 \mathrm{mV} \mathrm{s}^{-1}$.

Figure 4 shows a set of typical voltammograms obtained for the $\mathrm{Au} / 0.001 \mathrm{M}$ of $\mathrm{Cu}\left(\mathrm{NO}_{3}\right)_{2}+0.01 \mathrm{M} \mathrm{KHT}(\mathrm{pH}=3.5)$ system at different scan rates. At low scan rates, in the cathodic zone, the current density associated with peaks $A$ and $B$ increases with the increment of the scan rate. Also, in the anodic region, peak $A^{\prime}$ increases with the increasing of the scan rate; while peak $B^{\prime}$ is bigger at low scan rates, but decreases as the scan rate increases. Note that the charge associated with the formation of $\mathrm{Cu}\left(\mathrm{H}_{2} \mathrm{O}\right)_{4}^{+}$(peak $\mathrm{A}^{\prime}$ ) is much greater in comparison to the charge associated with the metallic copper dissolved in peak $\mathrm{B}^{\prime}$. This is because the metallic copper interacts with $\mathrm{Cu}\left(\mathrm{H}_{2} \mathrm{O}\right)_{6}^{2+}$ ions from the copper dissolved and the cupric ions present in the solution.

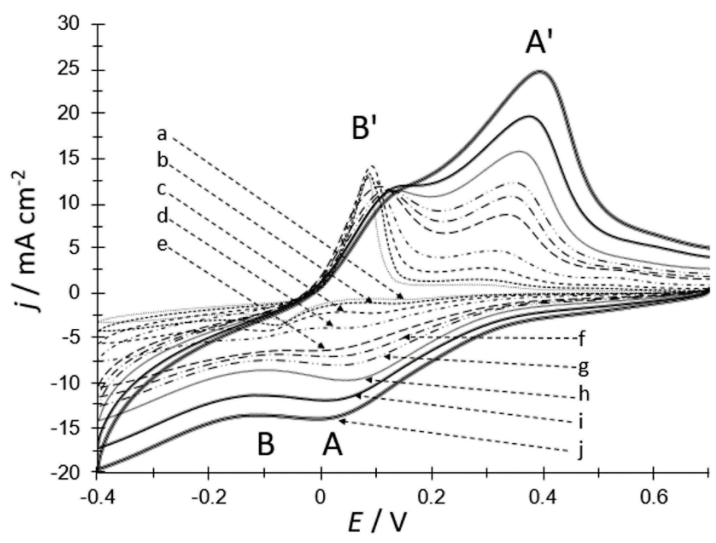

Figure 4. Cyclic voltammograms obtained from the $\mathrm{Au} / 0.001$ $\mathrm{M}$ of $\mathrm{Cu}\left(\mathrm{NO}_{3}\right)_{2}+0.01 \mathrm{M} \mathrm{KHT}(\mathrm{pH}=3.5)$ system at different scan potential rates of (a) 5, (b) 10, (c) 20, (d) 40, (e) 80, (f) 100, (g) 120, (h) 160, (i) 240 and (j) $320 \mathrm{mV} \mathrm{s}^{-1}$. In all cases the potential scan was started at $0.7 \mathrm{~V}$ toward the negative direction. 


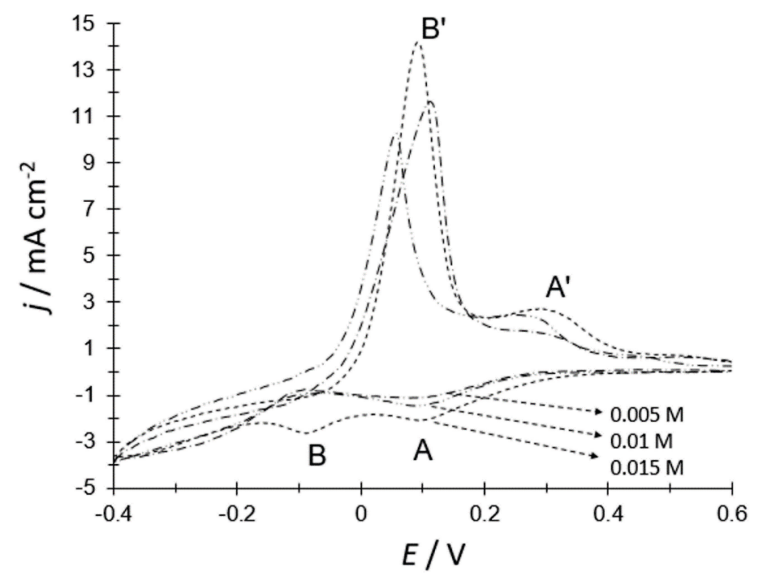

Figure 5. Cyclic voltammograms obtained from the Au/0.001 M of $\mathrm{Cu}\left(\mathrm{NO}_{3}\right)_{2}+x \mathrm{M} \mathrm{KHT}$ (where $x=0.005,0.01$, and 0.015) $(\mathrm{pH}=3.5)$ system at $20 \mathrm{mV} \mathrm{s}^{-1}$.

We also analyzed the effect of the concentration of HT ions in the electroplating bath, see Figure 5 . In all cases the voltammograms are characterized by two cathodic peaks ( $A$ and $B$ ) and two anodic peaks ( $A^{\prime}$ and $\left.B^{\prime}\right)$. If the concentration of the HT ions is increased, see Figure 5 , the current densities associated with peak $A$ and $B$ increase slightly.

In order to determine the type of control limiting of the processes $A$ and $B$, the current density $\left(j_{p}\right)$ value associated with these peaks was plotted as a function of $v^{1 / 2}$ (see Figure 6). ${ }^{[16,17]}$ In all cases a linear relationship was found, which is indicative of a diffusional controlled process. ${ }^{[16,17]}$

\section{Cronoamperometric Study}

Detailed information about the electrocrystallization process can be obtained from potentiostatic deposition. Figure 7 shows a set of current density transients recorded at different potentials from the $\mathrm{Au} / 0.001 \mathrm{M} \mathrm{Cu}\left(\mathrm{NO}_{3}\right)_{2}+0.005$ $\mathrm{M} \mathrm{KHT}(\mathrm{pH}=3.5)$ system. In all cases, the experiments involved the application of an initial potential of $0.650 \mathrm{~V}$ onto the gold electrode surface. After the application of this initial potential, a second negative potential step was applied to the electrode surface for $32 \mathrm{~s}$ within the range of 0.20 to $-0.160 \mathrm{~V}$ every $0.020 \mathrm{~V}$. It was also observed that the increasing KHT concentration in the plating bath does not change the overall behavior of the current density transients, see Figure 8 .

All the transients depicted in Figure 7 exhibit an exponential decay of the current to a constant value. Figure $7 a$ depicts the transients obtained at the range [0.2 to -0.060 ] $\mathrm{V}$, while in Figure $7 \mathrm{~b}$ are the transients obtained at the range $[0.0$ to -0.160$] \mathrm{V}$. The first range corresponds to the zone where it is formed the peak $A$, while the second one to the peak $B$, see Figure 2. Here, it is interesting to note that the transients depicted in Figure 7 , do not show the formation of a typical current density maximum related to a nucleation and growth process. ${ }^{[18,19]}$ Probably, it is caused by the strong adsorption of bitartrate ions onto the copper electrodeposited, which may favor the formation of copper layers instead copper clusters onto the gold surface. However, most experimental work is required to analyze the morphology and microstructure of these copper deposits; but that study is beyond of the scope of the present paper. Note, that the total current density transient consists of two parts: a capacitive current density, $j_{\text {dl }}$ (which charges the double layer), and a Faradaic current density, $j_{\mathrm{F}}$ (which corresponds to the rate of metal deposition). ${ }^{[20]}$ Hölze et al. have proposed that the current associated with the charge of the double layer is given by $j_{\mathrm{dl}}=k_{1} \exp \left(-k_{2} t\right)^{,{ }^{[21]}}$ where $k_{1}=k_{2} Q_{\mathrm{ads}}$ is the charge density a)

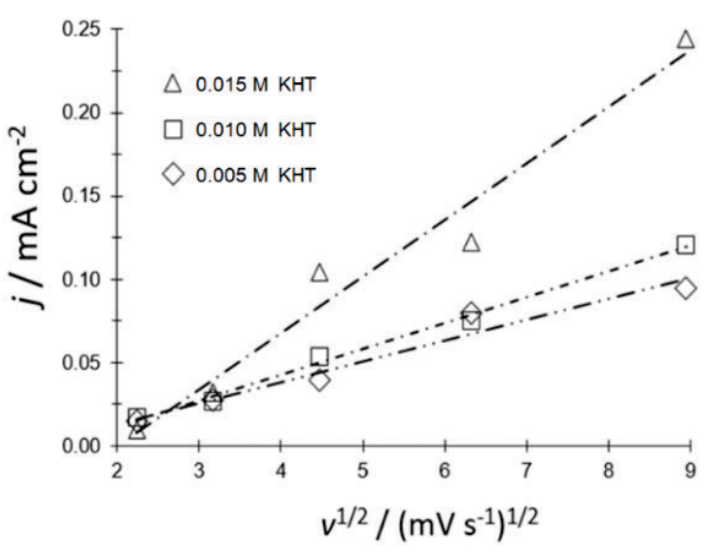

b)

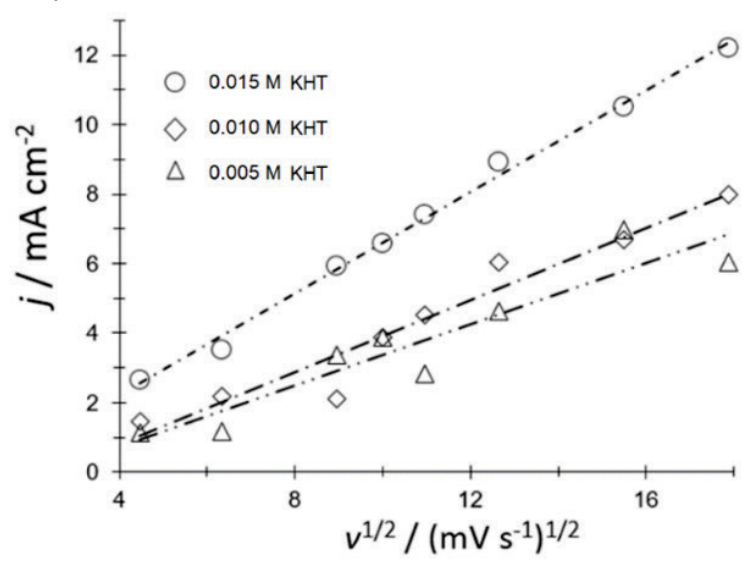

Figure 6. Plot of the experimental cathodic peak current density $\left(j_{p}\right)$ as a function of scan rate $\left(v^{1 / 2}\right)$ for a) peak $A$ and $\left.b\right)$ peak $B$, from the system $\mathrm{Au} / 0.001 \mathrm{M}$ of $\mathrm{Cu}\left(\mathrm{NO}_{3}\right)_{2}+x \mathrm{M} \mathrm{KHT}$ (where $x=0.005,0.01$, and $0.015 \mathrm{M}$, indicated in the Figure). The straight line corresponds to the linear fit to the experimental data. 


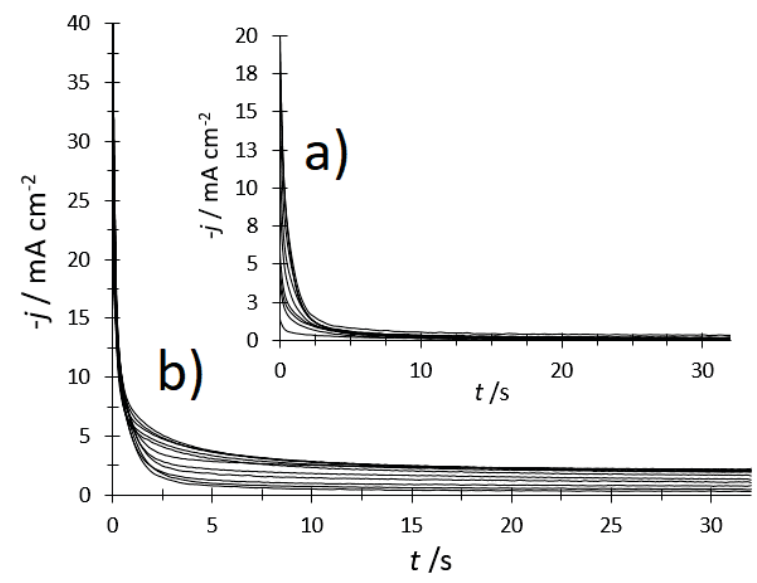

Figure 7. A set of experimental current density transients recorded from the $\mathrm{Au} / 0.001 \mathrm{M}$ of $\mathrm{Cu}\left(\mathrm{NO}_{3}\right)_{2}+0.005 \mathrm{M} \mathrm{KHT}$ $(\mathrm{pH}=3.5)$ system applying a potential step onto the gold electrode surface within the range of 0.200 to $-0.160 \mathrm{~V}$ every $0.020 \mathrm{~V}$ for $32 \mathrm{~s}$. a) transients obtained at the range $[0.2$ to $-0.060] \mathrm{V}, \mathrm{b}$ ) transients obtained at the range $[0.0$ to -0.160$] \mathrm{V}$.

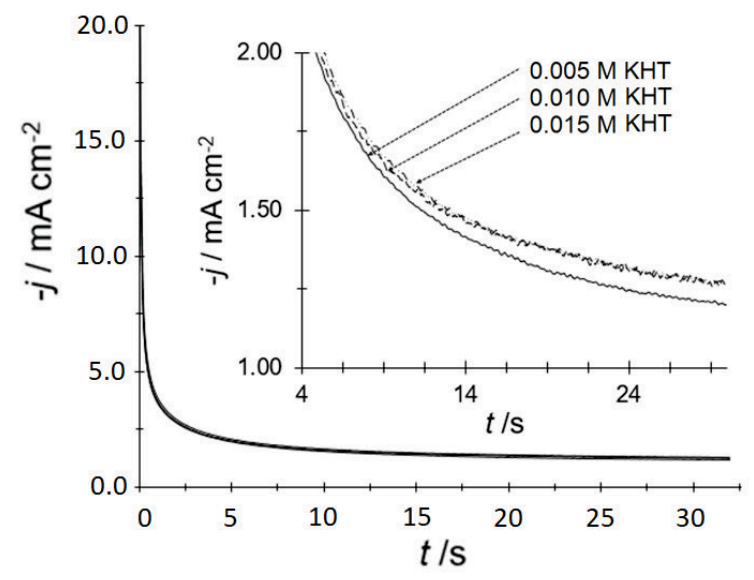

Figure 8. A set of experimental current density transients recorded from the $\mathrm{Au} / 0.001 \mathrm{M}$ of $\mathrm{Cu}\left(\mathrm{NO}_{3}\right)_{2}+x \mathrm{M} \mathrm{KHT}$ (where $x=0.005,0.01$, and $0.15 \mathrm{M}$ ) system applying a potential step onto the gold electrode surface of $-0.040 \mathrm{~V}$ for $32 \mathrm{~s}$ at the different KHT concentration indicated in the Figure. The inset shows a close up of the full transients depicted in the figure.

due to the adsorption process, while that, according to the shape of the transient, $j_{F}$ should be predicted by the Cottrell's equation. Therefore, it is proposed that the total current $\left(j_{T}\right)$ of the transient depicted in the Figure, may be predicted by:

$$
j_{\mathrm{T}}=j_{\mathrm{dl}}+j_{\mathrm{F}}=k_{1} \exp \left(-k_{2} t\right)+\frac{n F C \sqrt{D}}{\sqrt{\pi t}}
$$

where $n$ is the number of electrons transferred, $F$ is the
Faraday constant, $C$ is the copper concentration, and $D$ is the diffusion coefficient. Figure 9 depicts a non linear fitting of the experimental transient with one generated employing the Equation (8), note that there is a favorable comparison between the experimental and the theoretical transient. Similar fittings were obtained for the transients recorded at the different applied potentials and the KHT concentrations analyzed in the present work.

From these fittings, it was possible to find the diffusion coefficient values, as $2.3 \times 10^{-7} \mathrm{~cm}^{2} \mathrm{~s}^{-1}$ for $\mathrm{Cu}^{1+}$, while for $\mathrm{Cu}^{2+}$ is $2.96 \times 10^{-6} \mathrm{~cm}^{2} \mathrm{~s}^{-1}$. No significant differences were obtained when the KHT concentration was increased to $0.01 \mathrm{M}$ and $0.015 \mathrm{M}$. When the source of copper was $\mathrm{CuCl}_{2}$ the values of the diffusion coefficient values are $2.78 \times 10^{-7} \mathrm{~cm}^{2} \mathrm{~s}^{-1}$ for $\mathrm{Cu}^{1+}$, while for $\mathrm{Cu}^{2+}$ is $2.21 \times 10^{-6} \mathrm{~cm}^{2} \mathrm{~s}^{-1}$. In the case where $\mathrm{CuSO}_{4}{ }^{2-}$ was used, the values are $2.26 \times 10^{-7}$ $\mathrm{cm}^{2} \mathrm{~s}^{-1}$ for $\mathrm{Cu}^{1+}$, while for $\mathrm{Cu}^{2+}$ is $2.1 \times 10^{-6} \mathrm{~cm}^{2} \mathrm{~s}^{-1}$. These values compare favorably with those found for $\mathrm{Cu}^{1+}$ during the copper electrodeposition from aqueous ammoniacal solutions onto Stainless Steel[22] and from nitrate solutions on glassy carbon electrodes. ${ }^{[23]}$ In addition, we analyzed with an optical microscope, the formation of a copper electrodeposit, when a potential pulse of $-0.160 \mathrm{~V}$ was applied to the surface of the gold electrode immersed in a plating bath containing $0.001 \mathrm{M}$ of $\mathrm{Cu}\left(\mathrm{NO}_{3}\right)_{2}+0.005 \mathrm{M} \mathrm{KHT}$. Figure 10a depicts the gold electrode surface before the electrodeposition process, while Figure $10 \mathrm{~b}$ depicts the gold electrode surface after applying a potential pulse of $-0.160 \mathrm{~V}$ during 130 seconds. Moreover, we carried out a similar experiment from the system Au/0.005 M KHT (supporting electrolyte) and the image obtained is similar to Figure 10a, which suggests that the reddish brown color

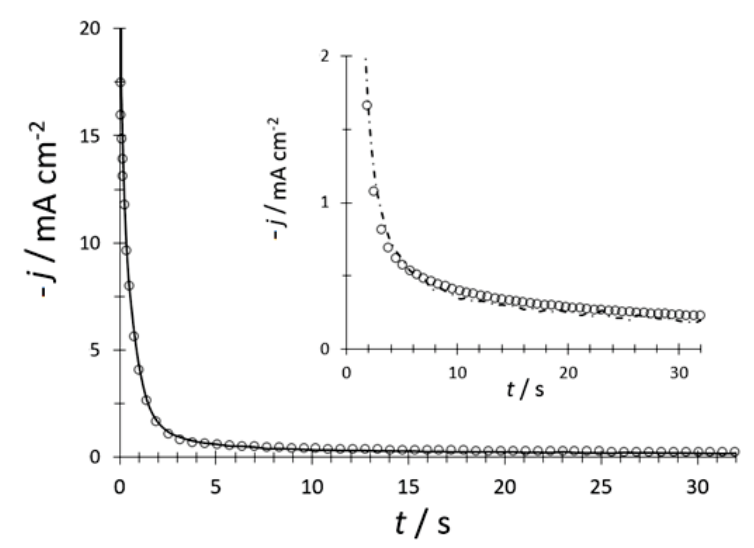

Figure 9. Comparison of an experimental current density transient (०००) recorded during copper electrodeposition process obtained at $0.060 \mathrm{~V}$ onto a polycrystalline gold electrode from the $\mathrm{Au} / 0.001 \mathrm{M}$ of $\mathrm{Cu}\left(\mathrm{NO}_{3}\right)_{2}+0.005 \mathrm{M} \mathrm{KHT}$ at $\mathrm{pH}=3.5$ system. The inset shows a close up of the full transient depicted in the figure. 
a)

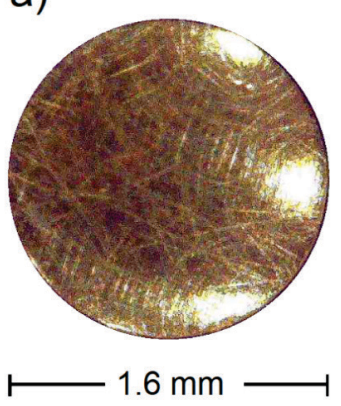

b)

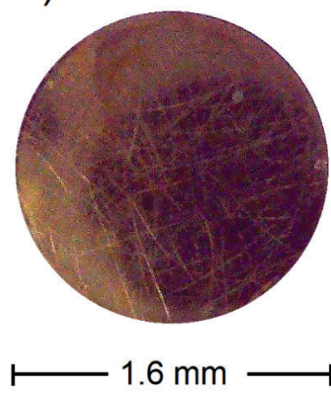

Figure 10. Optical microscope image at $50 \times$ magnification of a) a clean gold electrode surface b) a gold surface after applying a pulse potential of $-0.160 \mathrm{~V}$ during $132 \mathrm{~s}$.

observed in Figure 10b is related to the copper electrodeposited. The analysis of the microstructures formed will be studied in next works.

\section{CONCLUSIONS}

The copper electrodeposition process from an aqueous solution containing $0.001 \mathrm{M}$ of $\mathrm{CuX}$ (where $\mathrm{X}=\left(\mathrm{NO}_{3}{ }^{-}\right)_{2},\left(\mathrm{Cl}^{-}\right)_{2}, \mathrm{SO}_{4}{ }^{2-}$ and $x \mathrm{M} \mathrm{KHT}$ (where $x=0.005 \mathrm{M}, 0.01 \mathrm{M}$, and $0.015 \mathrm{M}$ ) was studied employing voltamperometric and potentiostatic techniques. The voltamperometric study suggests that the copper electrodeposition in the present system is a diffusioncontrolled process. The cronoamperometric study indicates that the electrodeposition process involves a capacitive and a faradaic contribution. An increment in the KHT concentration does not modify appreciably the values of the diffusion coefficient of the copper ions in the plating bath.

Acknowledgments. MH acknowledges CONACYT for the scholarship granted for Doctoral studies. Authors gratefully acknowledge financial support from CONACYT (project CB2015-257823) and to the Universidad Autónoma del Estado de Hidalgo. LHMH acknowledges to the SNI for the distinction of his membership and the stipend received.

\section{REFERENCES}

[1] J. W. Dini, D. D. Snyder, Electrodeposition of copper, in Modern Electroplating, Fifth Edition (Eds.: M. Schlesinger, M. Paunovic), John Wiley \& Sons Inc. 2010. https://doi.org/10.1002/9780470602638.ch2

[2] L. W. Flott, Met. Finish. 1996, 94, 55-58. https://doi.org/10.1016/0026-0576(96)84173-0

[3] A. Dumestre, T. Chone, J. Portal, M. Gerard, J. Berthelin, Appl. Environ. Microbiol. 1997, 63, 2729-2734. https://doi.org/10.1128/aem.63.7.2729-2734.1997

[4] M. A. M. Ibrahim, R. S. Bakdash, Surf. Coatings Technol. 2015, 282, 139-148. https://doi.org/10.1016/j.surfcoat.2015.10.024
[5] F. I. Lizama-Tzec, L. Canché-Canul, G. Oskam, Electrochim. Acta 2011, 56, 9391-9396. https://doi.org/10.1016/j.electacta.2011.08.023

[6] V. S. Kublanovsky, V. N. Nikitenko, K. P. Rudenko, 2013, 2013, 642-646.

https://doi.org/10.4236/ajac.2013.411076

[7] B. Hong, C. Jiang, X. Wang, Surf. Coatings Technol. 2007, 201, 7449-7452.

https://doi.org/10.1016/j.surfcoat.2007.02.011

[8] M. A. M. Ibrahim, R. S. Bakdash, Inter. J. Electrochem. Sci. 2015, 10, 9666-9677.

[9] J. C. Ballesteros, E. Chainet, P. Ozil, Y. Meas, G. Trejo, Int. J. Electrochem. Sci. 2011, 6, 2632-2651.

[10] V. Baliukienë, A. Survilienë, A. Survila, Chemija 2004, 15, 7-11.

[11] N. F. S. Zoecklein B. W., Fugelsang K. C., Gump B. H., Tartaric acid and its salts, in Prod. Wine Anal., Springer, Boston, MA., 1990, pp. 289-315. https://doi.org/10.1007/978-1-4615-8146-8_13

[12] S. Jayalakshmi, P. Venkatesh, P. Balaramesh, Int. J. Adv. Res. 2017, 53, 509-514.

https://doi.org/10.3103/S1068375517060023

[13] C. Lin, G.R. Darling, M. Forster, F. McBride, A. Massey, A. Hodgson. J. Am. Chem. Soc. 2020, 142(32), 13814-13822. https://doi.org/10.1021/jacs.0c04747

[14] D. Grujicic, B. Pesic, Electrochim. Acta 2005, 50, 4426-4443.

https://doi.org/10.1016/j.electacta.2005.02.012

[15] P. M. Vereecken, F. Vanden Kerchove, W. P. Gomes, Electrochim. Acta 1996, 41, 95-107.

https://doi.org/10.1016/0013-4686(95)00276-K

[16] J. E. B. Randles, Trans. Faraday Soc. 1948, 44, 327338. https://doi.org/10.1039/TF9484400327

[17] A. Ševčík, Collect. Czechoslov. Chem. Commun. 1948, 13, 349-377.

https://doi.org/10.1135/cccc19480349

[18] B. R.Scharifker, G. Hills, Electrochim. Acta 1983, 28, 879-889.

https://doi.org/10.1016/0013-4686(83)85163-9

[19] B. R. Scharifker, J. Mostany, Electroanal. Chem. 1984, 177, 13.

https://doi.org/10.1016/0022-0728(84)80207-7

[20] J. C. Puippe, N. Ibl, J. Appl. Electrochem. 1980, 10, 775-784. https://doi.org/10.1007/BF00611281

[21] M. H. Hölzle, V. Zwing, D. M. Kolb, Electrochim. Acta 1995, 40, 1237-1247.

https://doi.org/10.1016/0013-4686(95)00055-J

[22] J. Vazquez-Arenas, R. Cruz, L. H. Mendoza-Huizar, Electrochim. Acta 2006, 52, 892-903.

https://doi.org/10.1016/j.electacta.2006.06.022

[23] M. Aguilar-Sánchez, M. Palomar-Pardavé, S. CoronaAvendaño, M. A. Romero-Romo, T. Ramírez-Silva, B. Scharifker, J. Mostany, I. Rodriguez-Torres, ECS Trans. 2019, 20, 357-364. https://doi.org/10.1149/1.3268403 